\title{
THE
}

UNIVERSITY

University of Rhode Island

OF RHODE ISLAND

DigitalCommons@URI

9-29-2015

\section{Rapid and Efficient Pesticide Detection via Cyclodextrin-Promoted Energy Transfer}

\author{
Nicole Serio \\ University of Rhode Island \\ John Roque \\ University of Rhode Island \\ Andrew Badwal \\ University of Rhode Island \\ Mindy Levine \\ University of Rhode Island, m_levine@uri.edu
}

Follow this and additional works at: https://digitalcommons.uri.edu/chm_facpubs

The University of Rhode Island Faculty have made this article openly available.

Please let us know how Open Access to this research benefits you.

This is a pre-publication author manuscript of the final, published article.

Terms of Use

This article is made available under the terms and conditions applicable towards Open Access

Policy Articles, as set forth in our Terms of Use.

\section{Citation/Publisher Attribution}

Serio, N., Rogue, J., Badwal, A., \& Levine, M. (2015). Rapid and efficient pesticide detection via cyclodextrin-promoted energy transfer. Analyst, 140, 7503-7507. doi: 10.1039/C5AN01471A Available at: http://dx.doi.org/10.1039/C5AN01471A 


\section{Analyst}

\section{COMMUNICATION}

\section{Rapid and Efficient Pesticide Detection via Cyclodextrin- Promoted Energy Transfer}

Received 00th January 20xx Accepted 00th January 20xx

DOI: $10.1039 / \mathrm{x} 0 \mathrm{xx} 00000 \mathrm{x}$

www.rsc.org/

Cyclodextrins facilitate non-covalent fluorescence energy transfer from a variety of pesticides to high quantum-yield fluorophores, resulting in a rapid, sensitive detection scheme for these compounds with detection limits as low as two micromolar. Such a facile detection tool has significant potential applications in agriculture and public health research.

The sensitive, selective, and rapid detection of small-molecule pesticides is an important research objective, with implications for food and crop management, ${ }^{1}$ public health, ${ }^{2}$ and a variety of other scientific disciplines. ${ }^{3}$ Many small-molecule pesticides have known or suspected toxic health effects, including a variety of neurotoxic effects. ${ }^{4}$ Currently used methods for pesticide detection include gas chromatography-mass spectrometry (GC-MS) ${ }^{5}$ liquid chromatography-mass spectrometry (LC-MS), ${ }^{6}$ and surface-enhanced Raman spectroscopy (SERS). ${ }^{7}$ Fluorescence-based detection systems, including molecularly imprinted polymers, ${ }^{8}$ gold nanoparticles, ${ }^{9}$ and fluorescent polymers ${ }^{10}$ have also been developed, and in many cases lead to more sensitive detection limits and faster response times. ${ }^{11}$ While many of the currently used methods are highly sensitive for a particular class of pesticides, they often lack general applicability across multiple pesticide classes and across multiple environments (i.e. in soil, unprocessed harvested crops, and commercial food products). Moreover, accurate analysis using chromatographic based methods is often time-consuming and costly, requiring multiple extractions and separations to achieve optimal detection efficiencies. ${ }^{12}$

Previous research in our laboratory has focused on the development of cyclodextrin-promoted non-covalent energy transfer as a powerful tool for the sensitive and selective detection of a variety of carcinogenic small-molecule analytes. ${ }^{13}$ In these detection schemes, cyclodextrin promotes

\footnotetext{
a. Department of Chemistry, University of Rhode Island, 51 Lower College Road, Kingston, RI 02881; mlevine@chm.uri.edu; 401-874-4243

+ Footnotes relating to the title and/or authors should appear here.

Electronic Supplementary Information (ESI) available: Synthesis of fluorophore 8 detailed procedures for energy transfer and limit of detection experiments; summary tables and figures for all energy transfer and limit of detection experiments. See DOI: 10.1039/x0xx00000x
}

highly efficient energy transfer from a small molecule analyte to a high quantum yield fluorophore, resulting in a bright turnon fluorescence signal in the presence of the target analyte (Figure 1). This energy transfer scheme has been used successfully in complex systems such as biological fluids ${ }^{14}$ and crude oil collected in the aftermath of an oil spill. ${ }^{15}$ It has been used in the development of array-based detection schemes, ${ }^{16}$ and as part of tandem extraction-detection-detoxification environmental remediation schemes for environmental remediation efforts. ${ }^{17}$

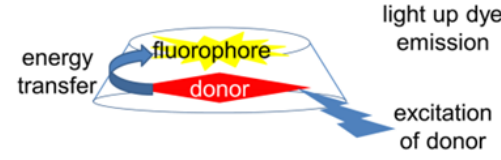

Fig. 1 Illustration of $\gamma$-cyclodextrin promoted energy transfer, wherein the analyte acts as an energy donor to a high quantum yield fluorophore acceptor.

Previous work in our group has focused primarily on highly fluorescent analytes such as polycyclic aromatic hydrocarbons (PAHs) that are known to act as efficient photophysical energy donors. However, even weakly photophysically active compounds such as polychlorinated biphenyls, tamoxifen, and diethylstilbestrol $^{18}$ participate efficiently in cyclodextrinpromoted energy transfer. Aromatic pesticides, including compounds 1-7 (Figure 2), are known to be weakly photophysically active, ${ }^{19}$ and are likely to participate in the same sorts of donor-acceptor interactions as other weakly photophysically active small molecule analytes. Reported herein is the use of these pesticides as energy donors in combination with high quantum yield fluorophore acceptors 810, and the ability to use such energy transfer as the basis for the highly sensitive detection of these pesticides in both purified buffer solution and in commercially available, unpurified apple juice.

The structures of all analytes and fluorophores are shown in Figure 2, and include multiple pesticide classes such as organochlorines (compounds $\mathbf{1}$ and 2), ${ }^{20}$ pyrethroids (compounds 3, 5, and 7), ${ }^{21}$ neonicotinoids (compound 4), ${ }^{22}$ and carbamates (compound 6). ${ }^{23}$ The fluorophores chosen are either commercially available or easily synthesized via literature- 
reported procedures; ${ }^{24}$ furthermore, their utility in energy transfer schemes has already been established. ${ }^{25}$
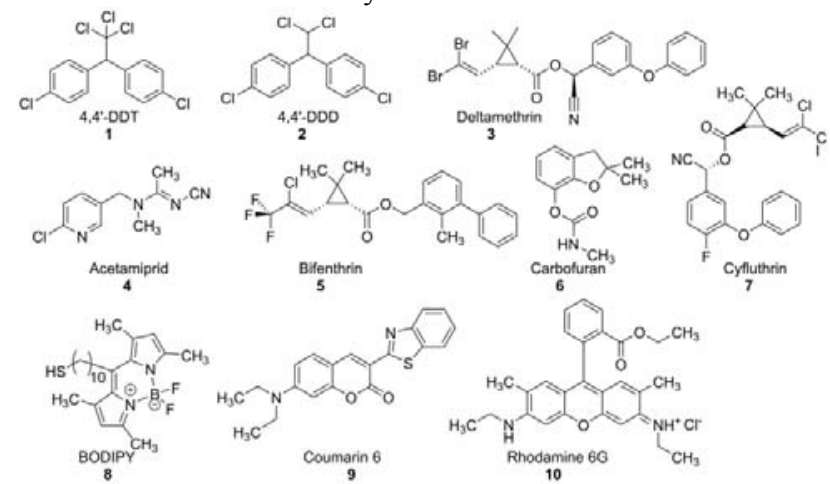

Fig. 2 Structures of pesticides (1-7) and fluorophores (8-10) investigated in this study.

For each energy transfer experiment, concentrated solutions of the pesticide and fluorophore in tetrahydrofuran were mixed in a phosphate buffered saline (PBS) solution containing $10 \mathrm{mM}$ $\gamma$-cyclodextrin and buffered at $\mathrm{pH} 7.4$, to create a solution that contained $91 \%$ aqueous solvent $(\mathrm{v} / \mathrm{v})$. This solution composition is designed to maximize hydrophobic association between the small molecule aromatic guests and the hydrophobic interior of the cyclodextrin cavity. ${ }^{26}$ Experiments in apple juice were conducted by replacing the PBS solution with a $1: 1(\mathrm{v} / \mathrm{v})$ mixture of $\gamma$-cyclodextrin in PBS and commercially available apple juice, which used without any purification.

The efficiency of energy transfer from the pesticide to the fluorophore was defined according to Equation 1:

$\%$ Energy transfer $=I_{\mathrm{DA}} / I_{\mathrm{A}} \times 100 \%$

(Eq. 1)

Where $I_{\mathrm{DA}}$ is the integrated emission of the fluorophore via analyte excitation, and $I_{\mathrm{A}}$ is the integrated emission of the fluorophore via direct excitation. ${ }^{27}$ As a control experiment, the $10 \mathrm{mM} \gamma$-cyclodextrin solution was replaced with a $0 \mathrm{mM}$ solution, to elucidate the role of $\gamma$-cyclodextrin in promoting the desired pesticide-to-fluorophore energy transfer. Selected results of these experiments are highlighted in Table 1.

Table 1. Selected energy transfer efficiencies from analytes 1-7 to fluorophore 8 in a phosphate-buffered saline solution ${ }^{\mathrm{a}}$

\begin{tabular}{cccc}
\hline & & & \\
\hline Analyte & Fluorophore & $10 \mathrm{mM} \gamma$-CD & $0 \mathrm{mM} \gamma$-CD \\
$\mathbf{1}$ & $\mathbf{8}$ & 8.2 & 8.7 \\
$\mathbf{2}$ & $\mathbf{8}$ & 9.2 & 8.7 \\
$\mathbf{3}$ & $\mathbf{8}$ & 22.2 & 17.7 \\
$\mathbf{4}$ & $\mathbf{8}$ & 43.3 & 27.5 \\
$\mathbf{5}$ & $\mathbf{8}$ & 54.9 & 25.4 \\
$\mathbf{6}$ & $\mathbf{8}$ & $b$ & $b$ \\
$\mathbf{7}$ & $\mathbf{8}$ & 48.7 & 39.6 \\
\hline
\end{tabular}

${ }^{\text {a }}$ All results represent the average of at least 3 trials

${ }^{\mathrm{b}}$ No real energy transfer peak was observed

These results divide the pesticides into two main classes: for compounds 1 and 2, the $\gamma$-cyclodextrin solution had a limited effect on the observed energy transfer efficiencies with essentially the same results observed in the absence and presence of $\gamma$-cyclodextrin, whereas for the majority of the pesticides, the energy transfer in the presence of $\gamma$-cyclodextrin was higher than that observed in the cyclodextrin-free solution. (Figures 3 and 4).

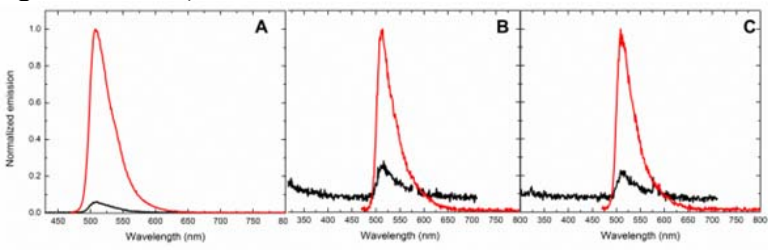

Fig. 3 Illustration of cyclodextrin-promoted energy transfer to fluorophore 8 from (t) excitation and the red line represents direct fluorophore excitation.

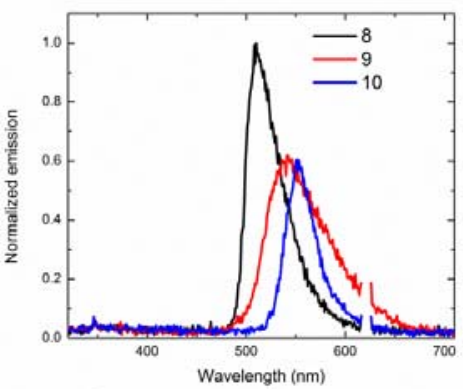

Fig. 4 Illustration of cyclodextrin promoted energy transfer from analyte $\mathbf{3}$ to

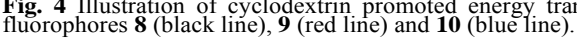

The differential behavior of pesticides $\mathbf{1}$ and $\mathbf{2}$ can be explained by their electrostatic potential surfaces (Figure 5), which indicate that the electron-rich face of the molecule (shown in blue) is buried in the interior pocket of the analytes and is not accessible for forming intermolecular contacts with the electron-deficient BODIPY fluorophore. This in turn leads to a limited degree of energy transfer from these pesticide donors, which is relatively unaffected by the addition of the cyclodextrin host structure. The other pesticides, in contrast, display more accessible electron-rich aromatic surfaces for electronically complementary electrostatic interactions with the non-covalently bound fluorophore acceptor.
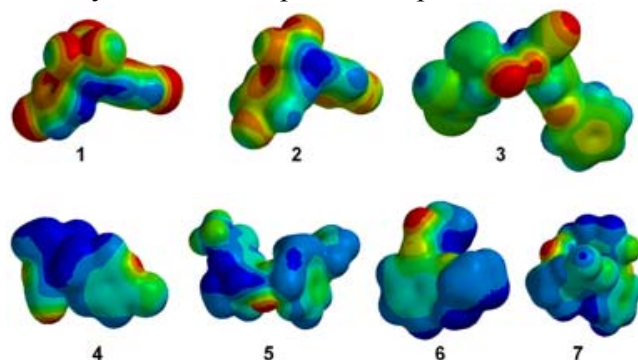

Fig. 5 Electrostatic potential surfaces of analytes 1-7. Computations were performed using Spartan's semi-empirical PM3 level calculations.

Moreover, most of the increased energy transfer efficiencies to fluorophore $\mathbf{8}$ in the presence of cyclodextrin are a result of the fact that the fluorophore emission via direct excitation $\left(I_{\mathrm{A}}\right.$ term in Equation 1) is markedly increased in the cyclodextrin-free solutions; this increase in $I_{\mathrm{A}}$, in turn, is responsible for the overall decreased energy transfer efficiencies (a ratio of $I_{\mathrm{DA}} / I_{\mathrm{A}}$ ) observed in the $0 \mathrm{mM} \gamma$-CD solutions (Table 2).

This increased fluorophore emission in the absence of cyclodextrin is in contrast to what is typically observed for 
host-guest systems, which generally demonstrate increased fluorescence intensity with higher concentration of the supramolecular host. ${ }^{28}$ Possible reasons for the anomalous behavior of fluorophore $\mathbf{8}$ in these systems include cyclodextrin-mediated aggregation of the fluorophore that decreases the overall fluorescence emission ${ }^{29}$ and/or hydrogen bonding between the fluorophore and the cyclodextrin that disrupts the core fluorophore architecture. ${ }^{30}$ Current efforts are focused on investigating these explanations in more detail.

Table 2. Changes in $I_{\mathrm{DA}}$ and $I_{\mathrm{A}}$ values between $10 \mathrm{mM} \gamma$-cyclodextrin and $0 \mathrm{mM} \gamma$ cyclodextrin buffered solutions $^{\mathrm{a}}$

\begin{tabular}{cccc}
\hline & & & \\
\hline Analyte & Fluorophore & $\Delta I_{\mathrm{DA}}{ }^{\mathrm{b}}$ & $\Delta I_{\mathrm{A}}{ }^{\mathrm{c}}$ \\
$\mathbf{1}$ & $\mathbf{8}$ & 1.05 & 0.99 \\
$\mathbf{2}$ & $\mathbf{8}$ & 0.96 & 1.01 \\
$\mathbf{3}$ & $\mathbf{8}$ & 0.87 & 1.09 \\
$\mathbf{4}$ & $\mathbf{8}$ & 1.14 & 1.79 \\
$\mathbf{5}$ & $\mathbf{8}$ & 0.59 & 1.27 \\
$\mathbf{6}$ & $\mathbf{8}$ & 1.06 & 1.60 \\
$\mathbf{7}$ & $\mathbf{8}$ & 1.01 & 1.24 \\
\hline
\end{tabular}

${ }^{a}$ All results represent the average of at least 3 trials

${ }^{\mathrm{b}} \Delta I_{\mathrm{DA}}=$ integrated fluorophore emission from analyte excitation in $0 \mathrm{mM} \gamma$ cyclodextrin solution divided by the integrated fluorophore emission from analyte excitation in a $10 \mathrm{mM} \gamma$-cyclodextrin solution

c $\Delta I_{\mathrm{A}}=$ integrated fluorophore emission from direct fluorophore excitation in 0 $\mathrm{mM} \gamma$-cyclodextrin solution divided by the integrated fluorophore emission from direct excitation in a $10 \mathrm{mM} \gamma$-cyclodextrin solution

Interestingly, fluorophore acceptors $\mathbf{9}$ and $\mathbf{1 0}$ demonstrated different behavior compared to fluorophore $\mathbf{8}$ (Table 3). For the case of fluorophore 9, most energy transfer efficiencies were higher in the absence of $\gamma$-cyclodextrin than in the $10 \mathrm{mM} \gamma$ cyclodextrin solution, which may reflect the fact that the fluorophore itself has strong cyclodextrin-free association and energy transfer with the pesticide acceptors due to its wellknown hydrophobic character; ${ }^{31}$ this energy transfer is then disrupted by the introduction of the cyclodextrin host.

Table 3. Selected energy transfer efficiencies from analytes 1-7 to fluorophore 9 in a phosphate-buffered saline solution $^{\mathrm{a}}$

\begin{tabular}{cccc}
\hline & & & \\
\hline Analyte & Fluorophore & $10 \mathrm{mM} \gamma$-CD & $0 \mathrm{mM} \gamma-\mathrm{CD}$ \\
$\mathbf{1}$ & $\mathbf{9}$ & $b$ & $b$ \\
$\mathbf{2}$ & $\mathbf{9}$ & $b$ & $b$ \\
$\mathbf{3}$ & $\mathbf{9}$ & 56.5 & 46.4 \\
$\mathbf{4}$ & $\mathbf{9}$ & 53.6 & 82.6 \\
$\mathbf{5}$ & $\mathbf{9}$ & 51.6 & 65.4 \\
$\mathbf{6}$ & $\mathbf{9}$ & $b$ & $b$ \\
$\mathbf{7}$ & $\mathbf{9}$ & 44.8 & 76.6 \\
\hline
\end{tabular}

${ }^{\text {a }}$ All results represent the average of at least 3 trials

${ }^{\mathrm{b}}$ No real energy transfer peak was observed

Fluorophore 10 demonstrated essentially no difference in energy transfer efficiencies in the presence or absence of $\gamma$ cyclodextrin (Table 4), even though fluorophore $\mathbf{1 0}$ has been reported to bind in the $\gamma$-cyclodextrin cavity with a $\mathrm{K}_{\mathrm{a}}=302 \mathrm{M}$ ${ }^{1}{ }^{32}$ In this case, control experiments suggest that what looks like an energy transfer peak is simply a result of exciting the fluorophore at a wavelength where it has non-zero absorption, as the same fluorescence emission peak from indirect excitation was observed in the presence and absence of the analyte (see ESI for more details).

Table 4. Selected energy transfer efficiencies from analytes 1-7 to fluorophore $\mathbf{1 0}$ in a phosphate-buffered saline solution $^{\mathrm{a}}$

\begin{tabular}{cccc}
\hline Analyte & Fluorophore & $10 \mathrm{mM} \gamma$-CD & $0 \mathrm{mM} \gamma$-CD \\
$\mathbf{1}$ & $\mathbf{1 0}$ & 4.0 & 4.0 \\
$\mathbf{2}$ & $\mathbf{1 0}$ & 5.0 & 4.2 \\
$\mathbf{3}$ & $\mathbf{1 0}$ & 9.2 & 8.9 \\
$\mathbf{4}$ & $\mathbf{1 0}$ & 5.3 & 5.5 \\
$\mathbf{5}$ & $\mathbf{1 0}$ & 8.7 & 11.9 \\
$\mathbf{6}$ & $\mathbf{1 0}$ & 11.2 & 13.6 \\
$\mathbf{7}$ & $\mathbf{1 0}$ & 8.9 & 16.1 \\
\hline
\end{tabular}

${ }^{\text {a }}$ All results represent the average of at least 3 trials

Efforts to extend the practicality of this detection system led to an evaluation of cyclodextrin-promoted energy transfer for pesticide detection in commercially available apple juice (Figure 6). The detection of pesticides in food and beverages such as apple juice is important for monitoring consumer consumption of and exposure to these pesticides. ${ }^{33}$ For most of the pesticide-fluorophore combinations investigated herein, extremely noisy fluorescence spectra (possibly due to the presence of particulate matter) precluded us from effectively determining the efficiency of pesticide-to-fluorophore energy transfer. However, pesticides $\mathbf{1}$ and $\mathbf{2}$ demonstrated moderate energy transfer efficiencies even in such a complex environment (Table 5). Limits of detection (LODs) and limits of quantification (LOQs) for these combinations were calculated following literature-reported procedures, ${ }^{7}$ and the results summarized in Table 5 are in line with or better than many currently utilized pesticide detection methods. ${ }^{34}$

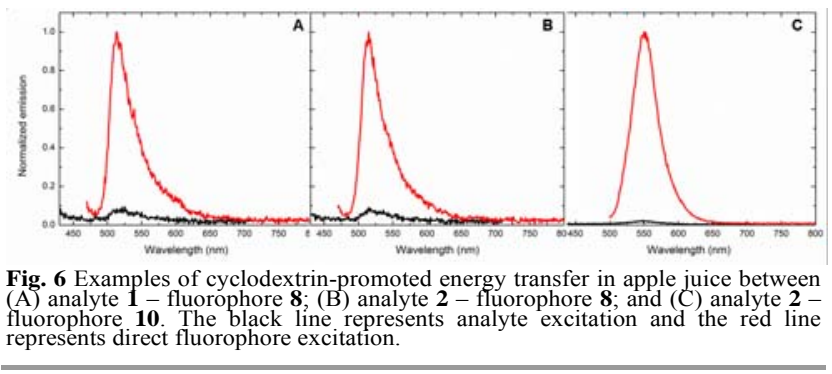

Table 5. Selected energy transfer efficiencies from analytes $\mathbf{1}$ and $\mathbf{2}$ to fluorophores 8-10 in a $10 \mathrm{mM} \gamma$-cyclodextrin in apple juice solution ${ }^{\mathrm{a}}$

\begin{tabular}{ccccc}
\hline & & & & \\
\hline Analyte & Fluorophore & Energy Transfer & LOD $(\mu \mathrm{M})^{\mathrm{b}}$ & LOQ $(\mu \mathrm{M})^{\mathrm{b}}$ \\
$\mathbf{1}$ & $\mathbf{8}$ & 25.0 & 14.2 & 50.4 \\
$\mathbf{1}$ & $\mathbf{1 0}$ & 4.8 & 6.4 & 11.5 \\
$\mathbf{2}$ & $\mathbf{8}$ & 24.3 & 2.1 & 45.1 \\
$\mathbf{2}$ & $\mathbf{1 0}$ & 4.9 & 5.5 & 6.8 \\
\hline
\end{tabular}

${ }^{a}$ All results represent the average of at least 3 trials

${ }^{\mathrm{b}}$ LODs and LOQs were calculated according to literature procedures.

In conclusion, reported herein is the rapid and sensitive detection of aromatic pesticides via cyclodextrin-promoted energy transfer to high quantum yield fluorophores, which was 
particularly successful using fluorophore $\mathbf{8}$ as an energy acceptor for pesticides 1-5 and 7. This detection method has a number of advantages compared to previously reported detection methods, including high sensitivity, rapid response time, and applicability across multiple classes of pesticides. Applications of this detection strategy in more complex systems and in the development of a practical detection device is currently under investigation, and results of these and other experiments will be reported in due course.

\section{Acknowledgements}

Funding for this research was provided by the University of Rhode Island start-up funding to M. Levine.

${ }^{1}$ M. R. Douglas and J. F. Tooker, Environ. Sci. Technol., 2015, 49, 5088; M. R. Berenbaum, J. Agricultur. Food Chem., 2015, Ahead of Print; DOI: 10.1021/acs.jafc.5b01067.

${ }^{2}$ V. Tomer, J. K. Sangha and H. G. Ramya, Proc. Natl. Acad. Sci. India, 2015, 85, 451; A. Ewence, S. Brescia, I. Johnson and P. C. Rumsby, Food Chem. Toxicol., 2015, 78, 214.

${ }^{3}$ T. B. Coles and M. W. Dryden, Parasites Vectors, 2014, 7, 8/1. ${ }^{4}$ L. Liu, Adv. Mater. Res., 2012, 518-523, 2045; S. Mostafalou and M. Abdollahi, Toxicol. Appl. Pharmacol., 2013, 268, 157. ${ }^{5}$ D. Y. Shinggu, O. N. Maitera and J. T. Barminas, Int. J. Pure Appl. Chem., 2015, 5, 150; M. Tavakoli, M. Hajimahmoodi and F. Shemirani, Anal. Methods, 2014, 6, 2988.

${ }^{6}$ A. Zgair, J. C. M. Wong, A. Sabri, P. M. Fischer, D. A. Barrett, C. S. Constantinescu and P. Gershkovich, J. Pharmaceutical Biomed. Anal., 2015, 114, 145.

${ }^{7}$ B. Saute and R. Narayanan, J. Raman Spectroscopy, 2013, 44, 1518.

${ }^{8}$ Y. Ma, S. Xu, S. Wang and L. Wang, TrAC, Trends Anal. Chem., 2015, 67, 209; A. L. Jenkins, R. Yin and J. L. Jensen, Analyst, 2001, 126, 798.

${ }^{9}$ J. Du, B. Zhu, X. Peng and X. Chen, Small, 2014, 10, 3461.

${ }^{10}$ W. Lei, Z. Gu, W. Si, F. Wang and Q. Hao, J. Electrochem. Soc., 2013, 160, H502.

${ }^{11}$ D. M. Jameson, J. C. Croney and P. D. J. Moens, Methods Enzymology, 2003, 360, 1; L. B. McGown and K. Nithipatikom, Appl. Spectroscopy Rev., 2000, 35, 353.

${ }^{12}$ R. Zhao, Ed. S. Wang, Food Chemical Hazard Detection, 2014, 3; M. Laxmi, S. Ghosh, M. A. Raja and D. Banji, J. Drug Science, 2013, 1, 1.

${ }^{13}$ N. Serio, K. Miller and M. Levine, Chem. Commun., 2013, 49, 4821; T. Mako, P. Marks, N. Cook and M. Levine, Supramol. Chem., 2012, 24, 743.

${ }^{14}$ N. Serio, C. Chanthalyma, L. Prignano and M. Levine, Supramol. Chem., 2014, 26, 714.

${ }^{15}$ N. Serio and M. Levine, Marine Pollution Bull., 2015, Ahead of Print, DOI: 10.1016/j.marpolbul.2015.04.008; N. Serio, C. Chanthalyma, S. Peters, D. Levine and M. Levine, J. Inclusion
Phenom. Macrocyclic Chem., 2015, 81, 341; N. Serio, L. Prignano, S. Peters and M. Levine, Polycyclic Aromatic Compounds, 2014, 34, 561.

${ }^{16}$ N. Serio, D. F. Moyano, V. M. Rotello and M. Levine, Chem. Commun., 2015, 51, 11615.

${ }^{17}$ N. Serio, C. Chanthalyma, L. Prignano and M. Levine, ACS Appl. Mater. Interfaces, 2013, 5, 11951.

${ }^{18}$ K. Itami and J.-i. Yoshida, Bull. Chem. Soc. Japan, 2006, 79, 811; H.-Y. Chen, H.-S. Zhuang and G.-X. Yang, Anal. Methods, 2014, 6, 6925.

${ }^{19}$ P. Kueseng, C. Thammakhet, P. Thavarungkul and P. Kanatharana, Anal. Lett., 2011, 44, 787; K.-W. Yiu, C.-K. Lee, K.-C. Kwok and N.-H. Cheung, Environ. Sci. Technol., 2014, 48, 11591; A. Coly and J. J. Aaron, Analusis, 1996, 24, 107.

${ }^{20}$ B. Eskenazi, J. Chevrier, L. G. Rosas, H. A. Anderson, M. S. Bornman, H. Bouwman, A. Chen, B. A. Cohn, C. de Jager, D. S. Henshel, F. Leipzig, J. S. Leipzig, E. C. Lorenz, S. M. Snedeker and D. Stapleton, Environ. Health Perspectives, 2009, 117, 1359. ${ }^{21}$ C. Corcellas, E. Eljarrat and D. Barcelo, Organohalogen Compounds, 2014, 76, 226.

${ }^{22}$ J. E. Casida, J. Agricultural Food. Chem., 2011, 59, 2923.

${ }^{23}$ F. Kamel and J. A. Hoppin, Environ. Health Perspectives, 2004, 112, 950.

${ }^{24}$ J. L. Shepherd, A. Kell, E. Chung, C. W. Sinclar, M. S. Workentin and D. Bizzotto, J. Am. Chem. Soc., 2004, 126, 8329.

${ }^{25}$ K. Singh, G. Negi and G. C. Joshi, AIP Conference Proceedings, 2015, 1661, 110026/1; J. Saha, A. Datta Roy, D. Dey, S. Chakraborty, D. Bhattacharjee, P. K. Paul and S. A. Hussain, Spectrochim. Acta A, 2015, 149, 143.

${ }^{26}$ C. O. Mellet, J. M. G. Fernandez and J. M. Benito, Chem. Soc. Rev., 2011, 40, 1586.

${ }^{27}$ M. Levine, I. Song, T. L. Andrew, S. E. Kooi and T. M. Swager, J. Polym. Sci. A. Polym. Chem., 2010, 48, 3382.

${ }^{28}$ T. Ogoshi and A. Harada, Sensors, 2008, 8, 4961.

${ }^{29}$ A. Antony Muthu Prabhu, V. K. Subramanian and N.

Rajendiran, Spectrochim. Acta A, 2012, 96, 95.

${ }_{30}$ R. Rajaram, K. N. Sundararajalu and S. Meenakshisundaram, J. Fluorescence, 2011, 21, 521.

${ }^{31}$ X. Miao, Y. Li, I. Wyman, S. M. Y. Lee, D. H. Macartney, Y. Zheng and R. Wang, MedChemComm., 2015, 6, 1370; M.

Tortora, F. Cavalieri, P. Mosesso, F. Ciaffardini, F. Melone and C. Crestini, Biomacromolecules, 2014, 15, 1634.

${ }^{32} \mathrm{~S}$. Hamai and K. Sasaki, J. Inclusion Phenom. Macrocyclic Chem., 2003, 45, 19.

${ }^{33}$ Z. Wang, Q. Chang, J. Kang, Y. Cao, N. Ge, C. Fan and G.-F. Pang, Anal. Methods, 2015, Ahead of Print, DOI:

10.1039/C5AY01478F; S. Qian and H. Lin, Anal. Chem., 2015, 87, 5395 .

34 C. Fernandez-Ramos D. Satinsky, B. Smidova and P. Solich, TrAC, Trends Anal. Chem., 2014, 62, 69; S. Panseri, P. A. Biondi, D. Vigo, R. Communod, and L. M. Chiesa, Ed. I. Muzzalupo, Food Industry, 2013, 261. 